\title{
MODALIDADES DE REGULAÇÃO DA ATIVIDADE CIENTÍFICA: UMA COMPARAÇÃO ENTRE AS INTERPRETAÇÕES NORMATIVA, COGNITIVA E TRANSACIONAL DOS PROCESSOS DE INTEGRAÇÃO SOCIAL DA COMUNIDADE CIENTÍFICA
}

\author{
Marcos Antônio MatTedi* \\ Maiko Rafael Spiess*
}

\begin{abstract}
RESUMO: O artigo examina a questão dos padrões de regulação da atividade científica, por meio da análise do conceito de comunidade científica. Sustenta que a dimensão regulatória exercida pela comunidade científica sobre a atividade científica pode ser descrita a partir de três formas de interpretação do processo de socialização: a auto-regulação normativa, cognitiva e transacional. Para desenvolver este argumento, depois de uma breve introdução onde será contextualizada a especificidade do debate sobre a comunidade científica, inicialmente apresentaremos a interpretação formulada por Merton sobre o ethos científico. Em seguida, trataremos da interpretação feita por Kuhn sobre os paradigmas e, por último, consideraremos a interpretação proposta por Hagstrom sobre o modelo de troca. Para finalizar, apresentaremos algumas conclusōes sobre o alcance e significado da noção de comunidade para descrição da atividade científica, por meio da comparação das contribuições dos três autores.
\end{abstract}

Palavras-chave: Comunidade científica. Integração. Merton. Kuhn. Hagstrom.

* Doutor em Ciências Sociais e professor titular do Mestrado em Desenvolvimento Regional, da Fundação Universidade Regional de Blumenau (FURB). E-mail: mam@furb.br

* Mestre em Política Científica e Tecnológica pelo Instituto de Geociências da Universidade Estadual de Campinas (UNICAMP).E-mail: spiess@ige.unicamp.br 
Modalidades de regulação da atividade científica...

MODALITIES REgUlATING SCIENTIFIC ACTIVITY: A COMPARISON OF THE NORMATIVE, COGNITIVE AND TRANSACTIONAL INTERPRETATIONS OF THE SCIENTIFIC COMMUNITY'S SOCIAL INTEGRATION PROCESSES

ABSTRACT: This paper explores the issue of the regulation patterns of scientific activity through the analysis of the concept of 'scientific community'. It advocates that the regulation exerted by the scientific community on its activities can be described by three interpretations of the socialization process: normative, cognitive and transactional self-regulations. To develop this argument, after a brief introduction contextualizing the debate on the scientific community, we present Merton's interpretation of the scientific ethos and go through Kuhn's interpretation of paradigms before considering the exchange model proposed by Hagstrom. We then present some of our conclusions on the range and meaning of the concept of community to depict scientific activity through the comparison of these three author's contribution.

Key words: Scientific community. Integration. Merton. Kuhn. Hagstrom.

A problemática da educação no debate sobre a comunidade científica

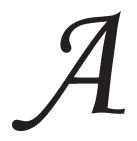

educação, entendida como um conjunto de práticas sociais por meio do qual os indivíduos aprendem a compreender a si mesmos e as relações estabelecidas com os contextos social e natural, vem se convertendo progressivamente na produção e transmissão de informações certificadas cientificamente. A produção e transmissão de conhecimento científico constituem uma atividade social que pressupõe a integração numa comunidade sociocultural. Os efeitos do processo de integração e operação institucional da comunidade científica repercutem diretamente na mediação entre os processos de ensinoaprendizagem (educação) e o contexto social (sociedade). Nessa integração, os processos de socialização próprios da comunidade científica não transmitem somente competências técnicas, mas também compromissos normativos que costumam ir muito além do conteúdo cognitivo, pois possuem uma influência mútua com o contexto social. Os mecanismos por meio dos quais a comunidade científica recruta os seus membros e reproduz estas competências têm sido explorados pelo que ficou conhecido como "nova sociologia do conhecimento", e pode ser 
exemplificado pelos estudos desenvolvidos por Bourdieu sobre o campo científico (1975), Latour, sobre os círculos de credibilidade (1997), e Knorr-Cetina, em termos de arenas transepistêmicas (1982). Contudo, no momento em que o debate a respeito da definição de regras sobre a forma de acesso aos fundos de pesquisa (a pesquisa a ser realizada) e aos mecanismos de divulgação (a pesquisa realizada) toma forma no meio acadêmico e se dissemina junto à opinião pública, parece importante acompanhar também não somente o sentido e o significado do seu desenvolvimento recente, mas também reconstruir as contribuiçōes precursoras que fundaram este debate e com as quais esta discussão se interpenetra.

Quando percorremos a história desse tipo de abordagem, em busca de estratégias analíticas que permitam descrever os mecanismos por meio dos quais a comunidade científica produz, transmite e aplica o conhecimento científico, bem como os dispositivos de recrutamento, formação e regulação de seus membros, nos deparamos com três estratégias que são, ao mesmo tempo sucessivas, mas também complementares. O interesse aqui não se reduz a simples transposição dos modelos analíticos que foram aplicados em outras esferas sociais, como, por exemplo, a política, a religião, o mundo urbano ou a educação, mas em fazer com que a própria atividade de pesquisa seja entendida como uma prática social constituída com base em padrões de interação social. Nesse sentido, tanto os trabalhos pioneiros desenvolvidos por Robert K. Merton sobre o ethos científico, quanto os trabalhos de Thomas S. Kuhn sobre os paradigmas, e os de Harry Hagstrom sobre o sistema de trocas, parecem tentar capturar, cada um a sua própria maneira, este processo de diferenciação da comunidade científica, por meio da caracterização dos mecanismos ou dispositivos internos de integração. A integração constitui um processo por meio do qual cada grupo social seleciona e incorpora seus membros e, dessa forma, possibilita sua reprodução por meio de uma relação recíproca de reivindicações e expectativas interdependentes.

Assim, considerando a organização social dos cientistas com base nas contribuiçôes de Merton, Kuhn e Hagstrom, pode-se argumentar que os processos podem ser descritos por meio de três padróes de integração: a) segundo Merton, através da integração normativa: compreende a abordagem que enfatiza o papel das normas como fator 
Modalidades de regulação da atividade científica...

determinante dos processos de integração da comunidade científica; b) segundo Kuhn, através da integração cognitiva: refere-se à abordagem que se baseia nos compromissos de ordem cognitiva como fator determinante dos processos de integração social; c) segundo Hagstrom, através da integração competitiva: diz respeito à abordagem que assinala que a integração da comunidade científica decorre de padrões de competição por recompensas.

O interesse da discussão das contribuições de Merton, Kuhn e Hagstrom sobre a comunidade científica e os padróes de integração social pode ser ilustrado pela simples lembrança de que, ainda hoje, os parâmetros de avaliação da produtividade e da inovação científica são estabelecidos por meio de indicadores bibliométricos, concebidos com base neste tipo de investigação (Callon, Courtial \& Penan, 1993). Isso indica que, apesar da discussão sobre a nova sociologia da ciência ultrapassar o debate sobre as formas de integração da comunidade científica, o contexto tecnocientífico nacional e internacional não invalida a oportunidade de reconstruir os fundamentos deste debate e ilustrar os fatores que estão em jogo.

Dessa forma, a descoberta de que a ciência não era uma atividade isolada de questionamento da natureza, mas sim uma atividade social, redefiniu a forma de configurar o problema do conhecimento, deslocando a atenção da relação entre o cientista e o mundo para as formas de interação entre cientistas. Para dar conta dessa forma de abordagem do problema do conhecimento, a atividade científica foi configurada por meio da aplicação da noção de comunidade científica. O conceito de comunidade constitui uma noção muito controversa (Baumgarten, 2004) e a forma como a noção de comunidade científica foi sendo formulada e reformulada, entre as décadas de 1930 e 1960, exprime a tentativa de caracterização dos processos de regulação que tornavam a atividade científica não somente possível, mas, sobretudo, específica. Com a aplicação da noção de comunidade científica procura-se indicar que algo era específico deste agrupamento social, nos mesmos termos em que se costumava caracterizar a comunidade familiar, comunidade residencial, comunidade religiosa, comunidade linguística, educacional etc., e assim isolar e compreender os padrões de interação e, portanto, de integração que a comunidade científica impunha para a prática da atividade científica. Nesse sentido, a análise da atividade científica, por meio da noção de comunidade científica, demonstrou que, como uma 
organização social, a ciência possui determinadas finalidades - como, por exemplo, o aumento e aplicação do conhecimento certificado - e, dessa forma, baseia-se num sistema de valores que enunciam regras e preceitos, e os faz respeitar por meio de recompensas e sanções, estabelecendo as condições de acesso e participação e, portanto, os padrões de regulação e integração.

Considerando as estratégias analíticas por meio das quais a noção de comunidade foi sendo formulada e reformulada, o presente artigo aborda a questão do processo de diferenciação organizacional e integração social da ciência, por meio das interpretações do conceito de comunidade científica formuladas por Merton, Kuhn e Hagstrom, e será divido em três partes principais. A primeira examina o modelo de integração normativa da comunidade científica proposto por Merton, por meio da análise e comparação das discussões sobre o ethos científico e as disputas por prioridades; a segunda parte aborda o modelo de integração cognitiva da comunidade científica concebido por Kuhn, por meio do exame da relação entre as noções de paradigma e ciência normal como especialidades disciplinares; na terceira parte do texto será considerado o modelo de integração formulado por Hagstrom, por meio de sua análise da regulação estabelecida pelo sistema de troca entre o cientista e a instituição científica. Para finalizar, será apresentada uma análise comparativa entre os três padrões de interpretação dos mecanismos de integração e considerado o significado para o desenvolvimento da abordagem social do problema do conhecimento em geral e da atividade científica em particular.

A comunidade científica como unidade normativamente integrada

O interesse de Merton na formação e desenvolvimento da comunidade científica reside na tentativa de explicar o seu processo de diferenciação como uma instituição social autônoma de outras instituições da sociedade moderna. Para o autor, as regras metodológicas que obrigam ao cientista fornecer evidências empíricas e consistência lógica nos resultados estão revestidas por normas morais apoiadas socialmente e possibilitam à ciência cumprir sua meta institucional de ampliação do conhecimento certificado. Ao perceber que a comunidade científica constitui uma atividade coletiva que se profissionalizou por meio de um processo de aprendizagem, socialização e interiorização de 
Modalidades de regulação da atividade científica...

normas, regras, saber-fazer, práticas comuns de trabalho e pela transmissão dos resultados obtidos, Merton efetua um deslocamento da análise dos efeitos externos que influenciam o desenvolvimento científico para análise da estrutura normativa interna da ciência. Dessa forma, acredita que as normas morais da ciência atuam como uma força que orienta a atividade científica, ou melhor, que delimita as fronteiras da ciência, pois, em seu ponto de vista, "o desenvolvimento científico da ciência somente ocorre em sociedades de certa ordem, submetidas a um complexo peculiar de pressupostos tácitos e de coaçóes institucionais" (Merton, 1970a, p. 637).

De acordo com o autor, "o ethos da ciência é esse complexo de valores e normas afetivamente totalizado, que se considera como constituindo uma obrigação moral para o cientista" (idem, ibid., p. 652). Essas normas podem ser expressas de diversas formas, como, por exemplo, prescrições, preferências e permissões, que legitimam a atuação do cientista, são transmitidas pelo preceito e reforçadas por sançôes, formando, assim, a consciência científica. Ainda que o "ethos da ciência" não esteja codificado, Merton acredita que ele pode ser inferido do consenso moral dos cientistas, por meio do conjunto de escritos e declaraçóes dos próprios cientistas a respeito da atividade que desenvolvem, expresso também na conduta dos cientistas por meio de atividades sancionadas positivamente, ou ainda, teoricamente necessárias, em virtude das relações funcionais com outras instituições. Para Merton, os mores da ciência são moralmente obrigatórios porque, além de serem eficazes, são considerados como bons e justos. $\mathrm{O}$ autor assinala a existência de quatro mores que guiam a atividade científica e integram a comunidade científica, normativamente:

a) universalismo: com este imperativo, Merton procura indicar que as pretensões de validade de qualquer enunciado cientifico devem obedecer a critérios impessoais pré-estabelecidos, adequando-se à observação empírica e ao conhecimento previamente confirmado. Nesse sentido, afirma que "encontra expressão no cânone de que as pretensões de verdade, quaisquer que sejam suas origens, têm que ser submetidas a critérios impessoais préestabelecidos: devem entrar em consonância com a observação e com o conhecimento previamente confirmado" (Merton, op. cit., p. 654). 
b) comunismo: com este imperativo, Merton (op. cit.) procura indicar que as descobertas e os avanços da ciência são produtos da colaboração social e constituem uma propriedade da humanidade. Uma lei ou uma teoria não constituem uma propriedade exclusiva do cientista. Nesse sentido, Merton afirma que "as descobertas da ciência são produto da colaboração social e estão destinadas à comunidade. Constituem herança comum em que os lucros do produtor individual estão severamente limitados. Uma lei e uma teoria não são propriedades exclusivas do seu descobridor e de seu herdeiro, nem costumes lhe concedem direitos de uso exclusivo" (p. 657).

c) desinteresse: ao enfatizar o papel do desinteresse, Merton procura assinalar que existe um padrão de controle institucional do comportamento dos cientistas que inibe os interesses pessoais, ou motivações de ordem extracientíficas. $\mathrm{O}$ caráter público da ciência obriga os cientistas a prestarem conta frente aos seus colegas, indicando que "ao cientista tem sido atribuída a paixão do saber, uma curiosidade ociosa, um interesse altruísta pelo benefício da humanidade e muitos outros motivos especiais" (p. 660).

d) ceticismo organizado: com este imperativo, Merton pretende indicar o caráter crítico da atividade científica e o fato de que o pesquisador científico não deve se ater a nenhum tipo de crença, pois "é um mandato ao mesmo tempo metodológico e institucional. A suspensão do julgamento até que os fatos estejam à mão e o exame imparcial das crenças, de acordo com os critérios empíricos e lógicos, têm envolvido periodicamente a ciência em conflitos com outras instituições” (p. 662).

Quase vinte anos após o estabelecimento dos "mores da ciência", num discurso proferido na Sociedade Americana de Sociologia, intitulado Priority in scientific discovery: a chapter of sociology of science, Merton retoma a problemática das normas na integração da comunidade científica, reformulando e complementando o "ethos da ciência". Rejeitando a interpretação dos conflitos e das controvérsias surgidas das descobertas simultâneas e das disputas por prioridades em termos de psicologia individual, ele considera a cristalização e a extensão de posiçôes contrárias como influência de normas sociais. Nesse sentido, assinala que os conflitos surgidos na ciência são uma consequência da 
Modalidades de regulação da atividade científica...

instituição científica que valoriza a originalidade como um bem supremo, pois "se a instituição da ciência atribui grande valor somente na originalidade, cientistas costumam dar mais importância para a descoberta de prioridades" (Merton, 1996, p. 289-290). Como na instituição científica existe um sistema de recompensas (prêmios, prestígio, autoridade, reconhecimento, eponímias etc.), os cientistas são forçados a buscar originalidade em suas pesquisas. Considerando esses fatores, Merton introduz mais duas normas:

e) originalidade: com essa nova norma, Merton pretende indicar que a instituição científica prioriza o progresso do conhecimento. Portanto, a busca de originalidade incitaria os cientistas a conflitos sobre a prioridade, porém teria uma função positiva porque estimularia o avanço do conhecimento científico, que constitui o objetivo básico da instituição científica. Dessa forma, afirma que "a grande frequência de conflitos sobre prioridade não é resultado de trações meramente individuais dos cientistas, mas da instituição da ciência, que define a originalidade como um valor supremo e por meio disso faz do reconhecimento da originalidade um assunto maior" (Merton, 1957, p. 640).

f) humildade: Merton nota que os cientistas guiam-se por outro valor, ou melhor, pela norma institucional da humildade. Para o autor, a humildade como um valor institucional assume diversas expressões e uma das mais comuns é o hábito de agradecer as contribuições de seus predecessores, mas também quando os cientistas insistem em destacar seus limites e as limitações de sua pesquisa científica. Com este imperativo, Merton procura indicar a tendência dos cientistas a reconhecerem publicamente seus limites. Segundo o autor, "a norma socialmente obrigada de humildade é o ponto mais imediato, servindo, como ela faz, para reduzir o mau comportamento dos cientistas" (idem, ibid., p. 646).

Portanto, são as normas que tornam inteligíveis as ações dos cientistas, na medida em que foram institucionalizadas pela comunidade científica, tornando-se requisitos fundamentais para a produção e aceitação de afirmações confirmadas e logicamente consistentes sobre regularidades empíricas. Merton acredita que os métodos científicos tornam-se obrigatórios não porque constituem um procedimento 
eficiente no estabelecimento de regularidades, mas porque se acredita que são justos e bons. Conforme a comunidade científica foi se diferenciando do resto da sociedade, os cientistas foram deixando de justificar sua atividade por meio de valores religiosos, econômicos ou políticos, estabelecendo uma cultura própria. Mais precisamente, na medida em que a comunidade científica segue produzindo conhecimentos certificados, a integração normativa parece ser operativa na atividade científica, porque guia a forma como o cientista atua e pensa a respeito dos resultados alcançados por seus pares. Isso indica que as normas técnicas (cognitivas) encontram-se escoradas por normas morais (sociais) e que o comportamento racional produzido pelo respeito às normas técnicas encontra-se revestido por outro, irracional, relativo às normas sociais.

\section{A comunidade científica como uma unidade integrada cognitivamente}

Ao abordar historicamente a formação e desenvolvimento da comunidade científica, Kuhn observa que a existência de uma estrutura normativa não é suficiente para determinar a diferenciação da comunidade científica e mantê-la integrada, como acreditava Merton. Em seu ponto de vista, a comunidade científica se caracteriza não pelas prescriçôes normativas, mas pela coerência de conhecimentos. Esta integração se estabelece pelo compartilhamento de paradigmas, que compreenderiam "as realizações científicas universalmente reconhecidas que, durante algum tempo, fornecem problemas e soluções-modelo para uma comunidade de praticantes de uma ciência” (Kuhn, 1989, p. 13). Para o autor, são estas realizações que proporcionam à comunidade científica o fundamento para a prática da pesquisa, explicitando-se nos manuais de pesquisa, que apresentam a teoria e as aplicabilidades exemplares, e "servem, por algum tempo, para definir, implicitamente, os problemas e métodos legítimos de um campo de pesquisa para as gerações posteriores de praticantes da ciência” (idem, ibid., p. 30). Portanto, os paradigmas integram a comunidade cognitivamente ao atrair partidários que buscam refinar a exatidão de medida dos problemas, mas, principalmente, porque servem como "exemplos aceitos na prática que proporcionam modelos nos quais brotam tradições coerentes e específicas da pesquisa científica” (idem, ibid.). Mais precisamente, em seu ponto de vista, a diferenciação da comunidade 
Modalidades de regulação da atividade científica...

científica só é possível por meio de um paradigma, "que prepara basicamente o estudante para ser membro da comunidade científica" (idem), a partir de um treinamento teórico e experimental altamente rígido e estruturado que indica os modos de percepção e crenças.

Quando a pesquisa científica guia-se, por algum tempo, por paradigmas, o compromisso entre os cientistas dá origem a um padrão de integração da atividade científica que Kuhn caracteriza como "ciência normal”. Esta compreende a prática científica que procura ampliar o conjunto de conhecimentos dos fatos contemplados pelo paradigma e, dessa forma, "força a natureza a se encaixar dentro dos limites inflexíveis fornecidos pelo paradigma" (Kuhn, 1989, p. 44). Isso ocorre porque "a ciência normal não tem como objetivo trazer à tona novas espécies de fenômenos; na verdade, aqueles que não se ajustam aos limites do paradigma frequentemente nem são vistos" (idem, ibid., p. 45). Portanto, a integração compreende compromissos teóricos e metodológicos que tornam possíveis "a solução de todo tipo de quebra-cabeças instrumentais, conceituais e matemáticos” (p. 55). É por isso que Kuhn afirma que "uma comunidade científica, ao adquirir um paradigma, adquire igualmente um critério para a escolha de problemas que, enquanto o paradigma for aceito, poderemos considerar como dotado de uma soluçãa” (p. 60). Dessa forma, quanto mais dogmático for o processo de treinamento ao qual os cientistas forem submetidos, mais coerente e eficaz se torna a comunicação científica, porque menor será a especulação.

Entre os principais padrōes, Kuhn destaca: a) generalizaçôes simbólicas (são expressões utilizadas pela comunidade científica de forma consensual, tais como símbolos, fórmulas e conceitos); b) compromissos coletivos (relações do grupo para com determinados princípios que auxiliam a apontar o que é aceitável ou não numa explicação); c) valores compartilhados (critérios compartilhados, tais como acuidade, simplicidade, coerência interna, plausibilidade etc.). Em suas palavras,

A existência dessa sólida rede de compromissos ou adesões - conceituais, teóricas, metodológicas e instrumentais - é uma das fontes principais da metáfora que relaciona a ciência normal à resolução de quebra-cabeças. Esses compromissos proporcionam ao praticante de uma especialidade amadurecida regras que lhe revelam a natureza do mundo e de sua ciência, permitindo-lhe assim concentrar-se com segurança nos problemas 
esotéricos definidos por tais regras, e pelos conhecimentos existentes. Nessa situação, encontrar a solução de um quebra-cabeça residual constitui um desafio pessoal do cientista. (Kuhn, 1989, p. 66)

Com o enfraquecimento do paradigma vigente e, consequentemente, a flexibilização dos compromissos compartilhados para concepção e resolução de quebra-cabeças, emerge um novo candidato a paradigma. Contudo, a transição para um novo paradigma não é um processo cumulativo obtido por meio da articulação, alteração ou adequação do paradigma anterior, mas pela reconstrução dos compromissos da comunidade, com base em novos princípios cognitivos. Estas crises, que dissolvem os compromissos coletivos e provocam a substituição do paradigma mais antigo pelo mais novo, o autor as caracteriza como "revoluções científicas". Estas revoluções compreendem um processo de desenvolvimento não-cumulativo, no qual os novos compromissos se revelam incompatíveis com os anteriores. Para ilustrar, o autor traça uma comparação com as revoluções políticas:

As revoluções políticas iniciam-se com um sentimento crescente, com frequência restrito a um segmento da comunidade política, de que as instituições existentes deixaram de responder adequadamente aos problemas postos por um meio que ajudaram em parte a criar. De forma muito semelhante, as revoluções científicas iniciam-se com um sentimento crescente, também seguidamente restrito a uma pequena subdivisão da comunidade científica, de que o paradigma existente deixou de funcionar na exploração de um aspecto da natureza, cuja exploração fora anteriormente dirigida pelo paradigma. Tanto no desenvolvimento político como no científico, o sentimento de funcionamento defeituoso, que pode levar à crise, é um pré-requisito para a revolução. (Idem, ibid., p. 126)

Assim como a escolha entre instituições políticas em competição, a escolha entre paradigmas em competição demonstra ser uma opção entre modos incompatíveis de vida comunitária, porque contrapõe compromissos cognitivos irreconciliáveis.

À medida que os problemas mudam, mudam também, seguidamente, os padrões que distinguem uma verdadeira solução científica de uma simples especulação metafísica, de um jogo de palavras ou de uma brincadeira matemática. A tradição científica normal que emerge de uma revolução científica é não somente incompatível, mas muitas vezes verdadeiramente incomensurável com aquela que a precedeu. (Idem, ibid., p. 138) 
Modalidades de regulação da atividade científica...

É por isso que, para Kuhn, a comunidade científica se forma e desenvolve como uma sucessão de paradigmas, que definem cientificamente os padrōes válidos para formulação e resolução de problemas. $\mathrm{O}$ autor afirma que "os membros do grupo, enquanto indivíduos em virtude de seu treino e experiência comuns, devem ser vistos como os únicos conhecedores das regras do jogo ou de algum critério equivalente para julgamentos inequívocos" (op. cit., p. 211). É por isso que uma comunidade científica parece sempre preocupada em assegurar o crescimento do conhecimento de forma detalhada e contínua, pois isso a mantém integrada cognitivamente. É nesse sentido, portanto, que deve ser entendida a famosa passagem do Posfácio: "um paradigma é aquilo que os membros de uma comunidade partilham e, inversamente, uma comunidade científica consiste em homens que partilham um paradigma" (idem, p. 219); ou seja, a comunidade científica se mantém integrada porque os cientistas compartilham crenças a respeito de como proceder cientificamente. Se "um paradigma governa, em primeiro lugar, não um objeto de estudo, mas um grupo praticante da ciência" (p. 224), esta integração foi estabelecida cognitivamente pelo compromisso firmado pelos pesquisadores de uma especialidade.

A comunidade científica como uma unidade integrada competitivamente

A preocupação de Hagstrom não é mais porque a comunidade se diferenciou (Merton), ou o que é a diferenciação (Kuhn), mas como a comunidade científica se mantém diferenciada e, portanto, o seu interesse se desloca para o controle social interno da ciência. Hagstrom transpõe a seguinte pergunta: as "normas" e "paradigmas" seriam suficientes para manter a comunidade diferenciada? Sua resposta volta-se para os dispositivos por meio dos quais se estabelece a adequação dos cientistas às normas e paradigmas que caracterizam a comunidade científica. Esta adequação não se estabelece somente como consequência do processo de socialização ao qual o cientista é submetido para o exercício profissional da prática científica, ou pelo aprendizado, mas pela busca de reconhecimento. Portanto, para tentar explicar o tipo de mediação que liga a atuação do cientista individualmente às normas e valores da comunidade científica, o autor argumenta que a integração é de tipo transacional: a adequação do cientista se estabeleceria por meio 
de uma troca na qual este produziria informação enquanto a comunidade científica conferiria reconhecimento - a alocação de prestígio. Assim, a busca de reconhecimento induziria os cientistas a publicarem seus resultados e, para terem seus trabalhos aceitos pelos periódicos, seriam obrigados a respeitar as normas da ciência. Portanto, como a fonte de reconhecimento opera como fonte de controle na organização da ciência, o autor diferencia dois tipos de reconhecimento: institucional e elementar.

O institucional refere-se ao status e premiações atribuídos aos cientistas por meio dos canais formais de comunicação. Para descrever este tipo de reconhecimento, Hagstrom indica que a comunicação formal na ciência é efetuada por meio de revistas científicas, em detrimento de livros e eventos científicos. Segundo o autor, a informação transmitida por meio das publicações científicas em artigos é altamente específica, abordando, frequentemente, um problema ou um conjunto de problemas relacionados. Assim, para o autor, o reconhecimento institucional adequa-se às normas centrais da comunidade científica, porque somente o valor cognitivo dos artigos seria avaliado no momento da publicação, o que demonstraria a autonomia da comunidade em estabelecer as suas próprias normas. Um segundo tipo de reconhecimento institucional diz respeito às distinções como, por exemplo, os prêmios e medalhas. Em síntese, para o autor, existem dois tipos básicos de reconhecimento institucional: a) o prestígio adquirido pela publicação em periódicos especializados e, consequentemente, a quantidade de vezes que o trabalho é citado pelos pares; b) as honrarias coletivas que estabelecem distinção. Ambas as formas de reconhecimento teriam a função de reafirmar os objetivos coletivos e a solidariedade da comunidade científica, que autor denomina como "alocação de status de elite" (Hagstrom, 1965, p. 28).

Já o reconhecimento elementar diz respeito ao prestígio adquirido por canais informais de comunicação. Para descrevê-lo, o autor considera três tipos de situaçóes onde o reconhecimento elementar costuma ser atribuído. A primeira compreende as reuniôes e eventos nos quais as informações são repassadas, e o prestígio do pesquisador é indicado pelo tipo de intervenção que ele exerce; a segunda diz respeito a visitas às organizações ou laboratórios científicos, na condição de consultor ou, simplesmente, de observador; uma terceira situação refere-se à influência nas unidades organizacionais como, por exemplo, os 
Modalidades de regulação da atividade científica...

departamentos ou agências de financiamento. Para o autor, estas situações produzem contato informal que opera de maneira suplementar aos canais formais de comunicação. Neste tipo de canal, ele observa, existe um tipo maior de liberdade e o contato pessoal no qual os cientistas podem fazer sugestôes sobre a validade dos trabalhos, diminuindo as situações de competição e antagonismo e reforçando a crença na interdependência de suas atividades de pesquisa.

Para Hagstrom, a competição por reconhecimento pode ser comparada à competição por lucro no mercado, na medida em que a pesquisa considerada mais importante tende a atrair mais esforços e, portanto, ajuda a escolher as melhores técnicas. Assim, a intensidade da competição em áreas de importância central induz os cientistas a trabalharem com vistas a diferenciar seus produtos de pesquisa e ganhos, estabelecendo monopólio sobre um pequeno setor da área. Além disso, força certos cientistas a trabalharem em áreas de importância periférica, fazendo com que áreas menos populares não sejam negligenciadas, facilitando a alocação de recursos e trabalho na ciência. A pesquisa considerada mais importante seria aquela que possui consequências mais fundamentais para a ciência e para a tecnologia e, portanto, atrai mais pesquisadores. Porém, a competição tende a ter também efeitos nocivos para o sistema de troca e, consequentemente, para a integração da comunidade científica. Um dos eventuais problemas gerados pela competição seria o risco de "fabricação" de dados. Contudo, este seria relativamente pequeno devido à existência da replicação, tornando a cópia e a fraude facilmente identificáveis. Mas os cientistas que acreditam que podem ser antecipados tendem ao sigilo, o que comprometeria o sistema de troca e, dessa forma, o controle social da ciência. Para o autor, o segredo

Leva para a duplicação de esforços que podem ser feitos. Como foi assinalado, isto pode produzir uma redução da comunicação formal: o cientista pode apresentar somente os resultados e omitir seus métodos. Isto restringe a disseminação de novidades e a possibilidade de técnicas importantes, e também aumenta a dificuldade de determinar a validade dos resultados. Finalmente, o segredo diminui a solidariedade na comunidade científica como um todo e em particular em certas unidades.

Os cientistas podem achar que as normas de independência são irrelevantes, eles podem torna-se menos responsivos a sua comunidade de pares. 
A tendência nessa direção pode desenvolver-se em grandes organizações constituídas em torno de facilidades de pesquisa (Hagstrom, 1965, p. 91 e 143).

Hagstrom constata que especialidades com maior prestígio usualmente acabam atraindo mais reconhecimento ou mais pesquisadores, na medida em que aumentam as chances de receber honrarias científicas. Quando um cientista recebe uma honraria conhecida, não somente o seu prestígio aumenta, mas também o de sua especialidade. Nesse sentido, o ranking de prestígio de uma especialidade é uma manifestação do reconhecimento alcançado por indivíduos, e isso teria a função de controle social. "Os cientistas não somente têm uma percepção distorcida sobre o grau de consenso na comunidade científica contemporânea, eles têm também uma percepção distorcida sobre a unidade da pesquisa presente e passada" (idem, ibid., p. 279).

Tendo como base o controle social da ciência, exercido pela troca de informação por reconhecimento, o autor conclui que o maior tipo de desorganização da ciência é o que chama de "anomia organizada", ou seja, a situação que surge quando cientistas altamente especializados não possuem trabalhos interdependentes. A questão que emerge da aplicação deste modelo de análise é o dilema entre liberdade e controle. Como controlar a atividade dos cientistas sem destruí-la? Para o autor, o espírito científico tende a declinar, se o padrão básico de especialização continuar a se expandir, pois a ciência é uma província diferenciada funcionalmente, que é influenciada pela sociedade.

\section{Considerações finais}

Durante aproximadamente trinta anos, o debate sobre a formação, diferenciação e desenvolvimento da comunidade científica monopolizou o foco da investigação social da ciência. Esta centralidade reflete tanto o predomínio do modelo estrutural-funcionalista no desenvolvimento do pensamento sociológico no período, quanto a tentativa de delimitação de uma dimensão específica de abordagem sociológica do problema do conhecimento. Os efeitos cumulativos destes dois processos foram as preocupações com as formas de organização e com os padrôes de integração da organização social da ciência. Assim, por um lado, o exame da atividade científica concentrou-se na caracterização 
Modalidades de regulação da atividade científica...

das unidades de organização que tornam a ciência uma atividade social específica e, por outro, enfatizou os mecanismos de integração por meio dos quais se estabelece esta atividade social. No que se refere ao primeiro eixo, este padrão de investigação da ciência indica que a produção de conhecimento científico pressupõe a participação de uma coletividade denominada comunidade científica, ou seja, uma instituição social distinta das outras instituições. No que se refere ao segundo eixo, indica que a atividade científica constitui o resultado do processo de incorporação de determinados pressupostos. Isso teria como consequência o reconhecimento, por parte da sociedade, da especificidade da atividade científica e a formação de uma organização social que regulamenta a atividade científica, garantindo, assim, a reprodução de sua especificidade intrínseca. Em outras palavras, trata-se da formação e desenvolvimento do papel social do cientista e da configuração da organização do trabalho científico, criados pela existência de mecanismos específicos de socialização e transmissão de conhecimentos, com base num sistema próprio de controle e reconhecimento social.

Considerando este contexto analítico, as duas questóes ilustram e permitem comparar as modalidades de regulação da comunidade científica e os padrões de integração: a autonomização e a integração.

a) a primeira questão, que permite estabelecer uma relação comparativa entre Merton, Kuhn e Hagstrom, diz respeito à relação entre a ciência e outras instituiçóes sociais; diz respeito ao grau de autonomia que a comunidade científica desenvolve em relação a outras instituições sociais. Para Merton, a autonomia da comunidade científica cresce à medida que a ciência converte-se em uma instituição dotada de características normativas próprias e passa a legitimar a si mesma, por meio de suas próprias normas. Para Kuhn, a autonomia é maior nos períodos em que existe um consenso cognitivo em torno dos paradigmas da ciência normal, pois geraria uma coerência nos conhecimentos produzidos pela comunidade científica; em períodos de crise, apresenta uma maior permeabilidade a fatores extracientíficos. Quanto a Hagstrom, a autonomia da comunidade científica seria instituída e mantida pelo comprometimento estabelecido pela existência de um sistema próprio de recompensas, tanto formal quanto informal. Portanto, muito embora existam diferenças entre os 
três modelos explicativos, o que parece determinar a relação entre a ciência e outras instituiçôes sociais é o seu fechamento organizacional. Portanto, pode-se dizer que, mesmo partindo de pressupostos analíticos distintos, os autores parecem concordar que as comunidades científicas caracterizam-se por uma espécie de isolamento com relação às exigências de não-especialistas. Nesse sentido, é possível formular a hipótese de que quanto maior o fechamento da ciência em torno de seus próprios compromissos e pressupostos, maior a autonomia da comunidade científica frente o contexto social.

b) a segunda questão que permite estabelecer uma comparação entre os autores refere-se à estrutura e dinâmica da integração da comunidade científica. Esta questão está relacionada à diferenciação da atividade científica, por meio de mecanismos sociais que autorregulam e auto-organizam e que tornam possível que o cientista escreva para uma audiência de pares e que não precise se preocupar com as opiniōes de outros grupos sociais. Para ilustrar esta questão, basta considerar como se estabelecem os sistemas de divulgação do conhecimento científico e o de recompensas. Para Merton, o que une um cientista a uma comunidade não é a proximidade espacial dos grupos de pesquisa, mas o respeito a critérios e mecanismos sociais de validação do conhecimento científico, por meio de um controle institucionalizado. Para Kuhn, o paradigma une um grupo de praticantes, com base nas convençōes estabelecidas em torno da abordagem de um objeto de estudo, e fazer parte da comunidade científica é compartilhar os compromissos coletivos a respeito da formulação e resolução desse quebra-cabeça. No que se refere a Hagstrom, esse processo deriva da manutenção do controle pelos pares, em detrimento do controle burocrático exercido por outras instituições sociais. Trata-se, portanto, de traçar os tipos de relaçóes que se estabelecem entre o cientista e a instituição científica. Na ciência moderna, a atividade individual é mais acentuada, o que acaba resultando na progressiva diferenciação social que se manifesta através da especialização dos campos de conhecimento científico. Nesse sentido, a comparação entre os três tipos de integração descritos por Merton, Kuhn e Hagstrom 
Modalidades de regulação da atividade científica...

indica que a comunidade cria padróes para o exercício da atividade científica.

Como assinalamos anteriormente, as contribuições de Merton, Kuhn e Hagstrom parecem possuir "as qualidades de seus defeitos". Com frequência, ao valorizarem a autonomia e a integração da comunidade científica, pela ênfase nas dimensões normativa, cognitiva ou transacional, estas abordagens, apesar de subestimarem a multiplicidade de fatores que emergem na relação de influência mutua estabelecida entre o contexto social e a comunidade científica, permitem observar que a educação em geral e o ensino superior, em particular, constituem atualmente os processos de socialização que legitimam (simbólica e formalmente) a entrada dos indivíduos na comunidade científica e, por outro lado, que transmitem e perpetuam o ethos, normas ou valores desta comunidade. De modo geral, não existe membro da comunidade científica reconhecido por seus pares que não tenha atravessado um processo de socialização prévio (a educação superior). Dada a natureza eminentemente "universitária" da ciência brasileira, a distinção entre o ensino e a pesquisa torna-se pouco clara, uma vez que os papéis de educador e cientista se sobrepóem com facilidade neste contexto.

Recebido em julho de 2008 e aprovado em setembro 2009

\section{Referências}

BARNES, B. T.S. Kuhn and social science. New York: Columbia University, 1982.

BAUMGARTEN, M. Comunidade ou coletividades?: o fazer científico na era da informação. Política \& Sociedade, Florianópolis, n. 4, p. 97-136, 2004.

BOURDIEU, P. La espécificité du champ scientific et les conditions sociales du progress de la raison. Sociologie et Societés, Montreal, v. 7, n. 1, p. 91-118, 1975.

BUNGE, M. Sociologia de la ciencia. Buenos Aires: Sudamericana, 1998. 
CALLON, M.; COURTIAL, J.-P.; PENAN, H. La scientométrie. Paris: PUF, 1993.

COLOGNES, S.A. O problema da autonomia da ciência e das coletividades científicas. Episteme, Porto Alegre, v. 1, n. 2, p. 23-45, 1996. DIXON, B. A comunidade científica. In: DixOn, B. Para que serve a ciência? São Paulo: Nacional; EdUSP, 1976. p. 28-47.

DUTRA, L.H.A. Introdução à teoria da ciência. Florianópolis: UFSC, 1998. ENEBAKK, V. The three Merton theses. Journal of Classical Sociology, London, v. 7, n. 2, p. 221-238, 2007.

HAGSTROM, W.O. The scientific community. New York: Basic Books, 1965.

HESS, D. Science studies an advanced introduction. New York: New York University, 1997.

KNELLER, G.F. A comunidade científica. In: KNeller, G.F. (Org.). A ciência como atividade humana. Rio de Janeiro: Zahar; São Paulo: EDUSP, 1980. p. 182-204.

KNORR-CETINA, K. Scientific communities or transepistemic arenas of research?: a critique of quasi-economic models of science. Social Studies of Science, London, v. 12, n, 1, p. 101-130, 1982.

KNORR-CETINA, K. Merton's sociology of science: the first and the last sociology of science? Contemporary Sociology, Washington, DC, v. 20, n. 4, p. 522-526, 1991.

KROPF, S.P; LIMA, N.T. Os valores e prática institucional da ciência: as concepções de Robert Merton e Thomas Kuhn. História, Ciências, Saude, Rio de Janeiro, v. 5, n. 3, p. 565-581, 1999.

KUHN, T.S. A estrutura das revoluções cientificas. São Paulo: Perspectiva, 1989 .

KUHN, T.S. O caminho desde a estrutura. São Paulo: UNESP, 2006.

LATOUR, B.; WOOLGAR, S. Vida de laboratório. Rio de Janeiro: Relume-Dumará, 1997. 
Modalidades de regulação da atividade científica...

MATTEDI, M. Dilemas da simetria entre contexto social e conhecimento: a redefinição das modalidades de abordagem sociológica do problema do conhecimento. Política \& Sociedade, Florianópolis, n. 4, p. 41-79, 2004.

MATTEDI, M. Sociologia e conhecimento: introdução à abordagem sociológica do conhecimento. Chapecó: Argos, 2006.

MATTEDI, M. A sociologia da pesquisa científica: o laboratório científico como unidade de análise sociológica. Teoria \& Pesquisa, São Carlos, v. 16, n. 2, p. 51-69, 2007.

MERTON, R. Priorities in scientific discovery: a chapter in sociology of science. American Sociological Review, Aliso Viejo, Cal., v. 22, n. 6, p. 635-659, 1957.

MERTON, R. Sociologia: teoria e estrutura. São Paulo: Mestre Jou, 1970a.

MERTON, R. Science, technology and society in seventeenth-century England. New York: Harper, $1970 \mathrm{~b}$.

MERTON, R. On social structure and science. Chicago: University of Chicago, 1996.

TURNER, S. Merton's 'norms' in political and intellectual context. Journal of Classical Sociology, London, v. 7, n. 2, p. 161-178, 2007. 